of asymmetry are shifted in typical directions when the hypothesised RS+ gene is present. The gene may be absent, or when present its expression may be reduced by factors that influence early growth. Among the variables associated with reduction in the shift of the chance distribution for handedness are male gender, twinning, low birth weight, poor phonological processing (occurs in many people with dyslexia) and early brain lesions. These reductions must be detected against a base rate of non-right-handedness in about one-third of the general population. Differences in asymmetry are not causal, but rather the results of changes in the frequency or expression of the RS+ gene. They are not likely to be useful markers for any specific clinical disorder.

In schizophrenia, I have suggested that the gene may lose its directional coding and become 'agnostic' for right or left. Symptoms of schizophrenia are hypothesised to occur when speech cortex is impaired on both sides of the brain, as expected in $50 \%$ of the relevant genotypes. Until the RS+ gene and its variants are found, however, the theory remains a hypothesis.

Annett, M. (2002) Handedness and Brain Asymmetry: The Right Shift Theory. Hove: Psychology Press.

Crow, T. J. (1997) Schizophrenia as a failure of hemispheric dominance for language. Trends in Neurosciences, 20, 339-343.

Procopio, M. (200I) Handedness and schizophrenia genetic and environmental factors. British Journal of Psychiatry, 179, 75-76.

Sommer, I., Aleman, A., Ramsey, N., et al (200I) Handedness, language lateralisation and anatomical asymmetry in schizophrenia. Meta-analysis. British Journal of Psychiatry, 178, 344-351.

M. Annett School of Psychology, University of Leicester, University Road, Leicester LEI 7RH, UK

\section{Genetic variation in European suicide rates}

The fact that Hungary and Finland had among the highest reported suicide rates in Europe has led to speculations about the possible involvement of a common genetic factor in this phenomenon (Marušič \& Farmer, 2001). Both Finns and Hungarians, as some linguists believe, belong to the Finno-Ugrian family of ethnic groups, with certain similarities in their ancient language. The high suicide rates in the various groups of Finno-Ugrians

Table I Allelic distribution of serotonergic gene polymorphisms in selected populations

\begin{tabular}{|c|c|c|c|c|}
\hline \multirow[t]{2}{*}{ Population } & \multicolumn{2}{|c|}{$\begin{array}{l}\text { 5-HT transporter gene } \\
\text { S/L polymorphism }\end{array}$} & \multicolumn{2}{|c|}{$\begin{array}{c}\text { TPH gene } 218 \mathrm{~A} / \mathrm{C} \\
\text { polymorphism }\end{array}$} \\
\hline & S allele (\%) & L allele (\%) & Allele A (\%) & Allele C (\%) \\
\hline Hungarian & 48.8 & 51.2 & 46.4 & 53.6 \\
\hline Finnish & 33.0 & 67.0 & 35.0 & 65.0 \\
\hline British & 45.6 & 54.4 & 39.1 & 60.9 \\
\hline
\end{tabular}

5-HT, serotonin; TPH, tryptophan hydroxylase.

suggested to Kondrichin (1995) that 'during the early stages of Finno-Ugrian ethnogenesis certain behavioural traits predisposing to suicide became fixed in the gene pool'.

We (Hrdina \& Faludi, 2001) have examined the available molecular genetic data on serotonergic candidate genes and their allelic association with suicide (Nielsen et al, 1994; Du et al, 2000) for any similarities or differences in allelic frequencies between the various populations, particularly between Finns and Hungarians. A direct comparison between the findings of association between serotonergic gene polymorphism and suicidal behaviour is difficult, since in the reports of positive associations different phenotypes (suicide attempt, completed suicide) were investigated. However, if certain serotonergic gene variants increase the disposition for, or vulnerability to, suicide in some populations that share higher rates of suicide and that may share some similarities in their ethno-historical origins, then the frequency of these predisposing gene variants should be comparable in those populations.

Table 1 summarises the allelic distributions of serotonergic gene polymorphisms in some selected populations. It is clearly apparent that the allelic distributions of the two polymorphisms (5-HT transporter S/L polymorphism and tryptophan hydroxylase gene $218 \mathrm{~A} / \mathrm{C}$ polymorphism) are remarkably different in Hungarian and Finnish populations. In fact, the frequencies of the $\mathrm{S}$ and $\mathrm{L}$ alleles of the 5-HT transporter in the Hungarian subjects are closer to those found in the British population.

The limited scientific evidence so far would suggest that there is no Finno-Ugrian 'suicide gene' or a shared genetic risk factor. It is unlikely that such a complex phenomenon as suicidal behaviour is genetically determined by a single gene or even a few gene variants. A more likely scenario is that the genetic contribution to suicide will be represented by small size effects of many gene variants associated with processes involved in suicidal behaviour, and by interaction of these genetic factors with environmental ones.

Du, L., Faludi, G., Palkovits, M., et al (2000) Tryptophan hydroxylase gene $218 \mathrm{~A} / \mathrm{C}$ polymorphism is not associated with depressed suicide. International Journal of Neuropsychopharmacology, 3, 215-220.

Hrdina, P. \& Faludi, G. (200I) Of suicide and genes. Neuropsychopharmacologia Hungarica, 3, 53-58.

Kondrichin, S.V. (1995) Suicide among Finno-Ugrians. Lancet, 346, 1632-1633.

Marušič, A. \& Farmer, A. (200I) Genetic risk factors as possible causes of the variation in European suicide rates. British Journal of Psychiatry, 179, 194-196.

Nielsen, D. A., Goldman, D., Virkkunen, M., et al (1994) Suicidality and 5-hydroxyindoleacetic acid concentration associated with tryptophan hydroxylase polymorphism. Archives of General Psychiatry, 5I, 34-38.

P. Hrdina Institute of Mental Health Research at Royal Ottawa Hospital, II45 Carling Avenue,

Ottawa, Canada KIZ 7K4

\section{Chronic fatigue syndrome or neurasthenia?}

The interesting study reported by Hickie et al (2002) draws attention to the prevalence of ICD-10 neurasthenia (World Health Organization, 1992) in a large sample of the Australian general population. The authors' findings are of the utmost importance for clinicians concerned with the disabling effects of fatigue but also provide food for thought in the wake of the CFS/ ME Working Group (2002) report to the Chief Medical Officer. In this report, the term chronic fatigue syndrome/myalgic 
encephalomyelitis (CFS/ME) is used as an 'umbrella term' because of the 'need for patients and clinicians to agree a satisfactory term as a means of communication' but the concept of neurasthenia is not used. The report's authors state that CFS is 'widely used among clinicians' and seem to consider it to be a disorder more physical than psychiatric. Equally, CFS/ME is not included in DSM-IV (American Psychiatric Association, 1994) or ICD-10. On the other hand, neurasthenia as defined in the ICD10 is a psychiatric disorder whose main feature is 'persistent and distressing complaints of increased fatigue after mental effort, or persistent and distressing complaints of bodily weakness and exhaustion after minimal effort'. This fatigue could be associated with muscular aches, dizziness, tension headaches, sleep disturbances, irritability, dyspepsia and inability to relax. Neurasthenia includes 'fatigue syndrome' but excludes 'post viral fatigue syndrome'. Using ICD-10 criteria in the general population, Hickie $e t$ al (2002) found that $1.5 \%$ of the 10641 people who participated in the study met the criteria for neurasthenia in the past year. For females aged between 18 and 24 years, the 12 -month prevalence rises to $2.4 \%$.

If it is reasonable to compare the Australian and the British populations, we could probably expect a similar proportion of people here to be affected by this psychiatric disorder; the question here is what diagnosis is applied to them? If it is the case that CFS/ ME is suggested, this would have adverse implications both for these patients essentially in need of treatment for a psychiatric disorder, and for any research on the aetiology and the treatment of CFS/ME.

American Psychiatric Association (1994) Diagnostic and Statistical Manual of Mental Disorders (4th edn) (DSM-IV). Washington, DC: APA.

CFS/ME Working Group (2002) A Report of the CFS/ ME Working Group. Report to the Chief Medical Officer of an Independent Working Group. London: Department of Health. http. //www.doh.gov.uk/cmo/cfsmereport/ cfsmereport.pdf

Hickie, L., Davenport, T., Issakidis, C., et al (2002) Neurasthenia: prevalence, disability and health care characteristics in the Australian community. British Journal of Psychiatry, I8I, 56-61.

World Health Organization (1992) International Classification of Diseases and Related Disorders (ICD-10). Geneva: WHO.

L. Bailly University College London Medical School, Department of Psychiatry \& Behavioural Sciences, 4I Riding House Street, London WIN 8AA, UK

\section{Explanatory models in psychiatry}

Bhui \& Bhugra (2002) rightly identify the importance of eliciting patient explanatory models in routine clinical psychiatric practice. Also, they highlight the difficulties in applying this socio-anthropological perspective in routine clinical practice and mental health research. The reductionistic nature of psychiatric classifications, the inherent diversity within diagnostic categories, the fact that choice of therapy is not category-specific but is based on clinical presentation and symptoms, and the variability of outcomes demand the individualisation of care (Jacob, 1999). Bhui \& Bhugra attempt to address this complex reality related to mental illness by taking a pragmatic approach.

I agree with Bhui \& Bhugra that the transition from illness experience to disorder is determined by social decision points rather than biomedically determined levels of disorder. This is conceptually sound from a socio-anthropological point of view which has approached the issues from a sociocultural perspective. Hitherto, medical anthropologists and sociologists viewed individuals' explanatory models as alternatives to the biomedical model. This would be an oversimplified application of an anthropological perspective in psychiatric practice. Although individual explanatory models are arguably more appropriate, they are not alternatives. Given the incomplete understanding of mental illness by the scientific community, it is not clear whether explanatory models alone are able to capture the complex mental health needs of patients across cultures.

As Bhui \& Bhugra mentioned, in many cases the clinical reality is that individual explanatory models and biomedical diagnostic categories are not mutually exclusive but complementary. Medical/biological perspectives and cultural/anthropological views in isolation are inadequate for the understanding of mental disorders (Jacob, 1999). Examining the interconnection between the biomedical model and the individual explanatory model will produce a comprehensive assessment schedule that will be both internationally and locally valid and can form the basis of culturally appropriate modes of treatment that take into account the effect of culture, as well as individual differences, on courses and outcomes. This attempt may furnish the clinician with an opportunity to consider how best to help the patient.
Bhui, K. \& Bhugra, D. (2002) Explanatory models for mental distress: implications for clinical practice and research. British Journal of Psychiatry, 181, 6-7.

Jacob, K. S. (1999) Mental disorders across cultures: the common issues. International Review of Psychiatry, II, III-II5.

B. Saravanan Department of Psychiatry, Christian Medical College, Vellore 632 002, India

I read Drs Bhui \& Bhugra's (2002) editorial with interest. The authors advocate a socioanthropologically informed method for both clinical and academic psychiatry, an opinion with which I strongly agree and one that may have come to psychiatry earlier. If one returns to the pages of Jaspers' General Psychopathology (Jaspers, 1913, current edition in English translation 1997), and his seminal paper 'The phenomenological approach in psychopathology' (Jaspers, 1912), there is a clear tension between his claim to practise a phenomenology of mental illness, where the transcendentally ideal mental state abnormalities are elucidated and described, and his call to 'understand' the patient's symptoms in the light of their world view. This latter approach owes much to his mentor Weber's conception of 'ideal types' and there is a clear debt to the hermeneutics and historicism of Dilthey in his suggestion that Verstehen (variously translated as interpretive understanding or empathy) is the correct method for psychopathology, rather than the phenomenology of Husserl (Berrios, 1993). The approach of Husserl in Logical Investigations (1913, current edition in English translation 2001) could be described as the search for certain features of consciousness that are ideal, pure and $a$ priori and structure the meaning of experience and as such are true for all men at all times. Dilthey, in contrast, would argue for the contingency of world view which could only be viewed in others by a thorough, and possibly impossible, immersion in the meaningful structure of their lived environment - Verstehen (Outhwaite, 1986). This latter method is likely to be only partially successful, even in the hands of a very skilled practitioner, as in a very real sense, one's life can only ever be lived from 'within' and it is a question of degree as to how far an external observer could ever appreciate its subtleties. For the attempt to be made, however, would require a depth of knowledge of the various socio-anthropological models before an investigator could 